\title{
The Inventory Control System of Reverse Logistics for E-Commerce Packaging Recovery Based on BP Neural Network
}

\author{
Zhidan Qin \\ Research Center for Infant Products and Services Supply Chain, Chongqing University of Education, \\ Chongqing 400067, China \\ E-mail: qinzd@cque.edu.cn
}

Received: June 30, 2021. Revised: December 17, 2021. Accepted: January 11, 2022. Published: January 13, 2022.

\begin{abstract}
The paper combines BP neural network to optimize the control system of e-commerce packaging and reverse logistics inventory. Through improving the hardware configuration structure of the system, the system can be improved and the operation effect of the system can be improved. The software flow and operation algorithm of the storage control system of e-commerce packaging recycling reverse logistics are optimized step by step, and the logistics is delivered by following the vehicle on the spot and visiting the logistics The distribution personnel collect the relevant data and data in the process of logistics and transportation, draw the reverse logistics business flow chart, point out the situation of reverse logistics before and after the goods distribution and distribution due to the cancellation of orders or transactions by customers, and the application for return of goods after the transaction. Meanwhile, it points out that the sales return operation site in the reverse logistics management process is chaotic and not formed the clear business process specification and other problems can effectively control the reverse logistics inventory of e-commerce packaging recovery. Finally, the experiment proves that the e-commerce packaging recycling reverse logistics inventory control system is more practical in the practical application process, and fully meets the research requirements.
\end{abstract}

Keywords-BP neural network, e-commerce packaging, reverse logistics.

\section{INTRODUCTION}

$\mathrm{I}^{\mathrm{N}}$ recent years, the environmental problems are serious, people all over the world are exploring the mode of sustainable development, and reverse logistics has attracted much attention. From the economic point of view, reverse logistics can save resources and is conducive to sustainable economic development; from the social point of view, reverse logistics can establish a good corporate image in the hearts of consumers and benefit the society. At present, China's industry has entered a period of deep adjustment, and the overall development of the logistics industry is slow and smooth [1]. The rise of e-commerce has stimulated many changes in traditional business models. Compared with the traditional distribution mode, the introduction of e-commerce platform sales mode greatly shortens the circulation link, realizes the B2B transaction from the producer directly to the merchant, directly reduces the transportation and labor costs in the circulation process, and brings some other benefits for the producer and the final consumer. The rapid rise and development of the operation mode not only conforms to the situation, but also changes and innovates in the mode of operation and circulation. With the development of e-commerce platform, the research on e-commerce mode is more extensive. Enterprises often make inventory strategy based on the experience of previous years, which is easy to cause out of stock, out of stock or a large number of overstocking. Out of stock is easy to cause the loss of customers, and the high inventory makes the enterprise face huge financial pressure, which has a negative impact on the operation of the enterprise. We have carried out a comprehensive study.

Dutta et al. [2] proposed a multi-objective logistics network model for returned products in Indian e-commerce market. The multi-echelon supply chain is composed of customer markets, warehouses, delivery centers, landfills, incineration centers and recycling centers. Multi-objective optimization is carried out in three aspects of sustainability, that is, economy, represented by cost, environment, environmental impact of different processes, and sociality, represented by working days that are generated and lost due to injury at work. The Weighted Goal Programming (WGP) technique minimizes costs, environmental impacts, and maximizes social responsibility by weighing different goals. But this method is the traditional sales mode and network sales mode. Wang et al. [3] proposed outsourcing reverse logistics for e-commerce retailers: a two-stage fuzzy optimization approach. This method helps companies select and evaluate different third-party reverse logistics providers through a hybrid fuzzy multi-criteria decision (MCDM) method. Incorporate relevant standards on economic, environmental, social and risk factors into the model. The alternatives are then ranked using the fuzzy technique of order preference similar to the ideal solution. However, the control process of the modified method is more complicated, and the calculation efficiency needs to be further improved.

This paper analyzes the relevant theoretical knowledge of 
reverse logistics and inventory control, and summarizes the previous research results. Secondly, according to the basic situation of inventory management, this paper focuses on the analysis and research of the current situation and existing problems of inventory management. Finally, the traditional sales mode and network sales mode are distinguished, and the inventory control model based on reverse logistics is established respectively, and the optimal operation strategy is obtained. It is expected that through the analysis and research, it can play a positive reference for the cost control of manufacturing enterprises and the development of circular economy in China.

\section{THE INVENTORY CONTROL SYSTEM OF REVERSE LOGISTICS FOR E-COMMERCE PACKAGING RECOVERY}

\section{A. Hardware Configuration of Inventory Control System of Reverse Logistics}

The logistics activities of enterprises are mainly realized through two steps: Reverse Logistics on the one hand, and positive logistics on the other hand, but there are many links in concept. In the process of product management, enterprises usually distinguish and manage new products and recycled products, and adopt different management strategies and management methods [4]. On the enterprise level, the relationship between reverse logistics and forward logistics is quite deep, so we can not ignore the value of the positive logistics while we discuss the reverse logistics, because the existence of positive logistics is the basis of the discussion of reverse logistics. Whether it is positive logistics or reverse logistics, it is to meet the market demand and reduce the development cost of enterprises [5]. Through the establishment of reverse logistics inventory model, the paper discusses the problem and then obtains the answer through the model. The main purpose is to hope that the inventory cost of enterprises can be improved at a higher level [6]. The main purpose of reverse logistics control is to improve the utilization rate of recycled products through reverse logistics activities as much as possible, and reduce the inventory cost of the recovered products as much as possible. In order to realize rapid and intensive reverse logistics products turnover and ensure greater benefits in product recovery, it is necessary to improve the management of reverse logistics inventory [7]. From the development of reverse logistics, there are three main modes of reverse logistics. However, in the process of research, in order to further study the development of reverse logistics, the paper analyzes and studies the cost management of reverse logistics by using the mode of enterprise itself. The main framework is shown in Figure 1.

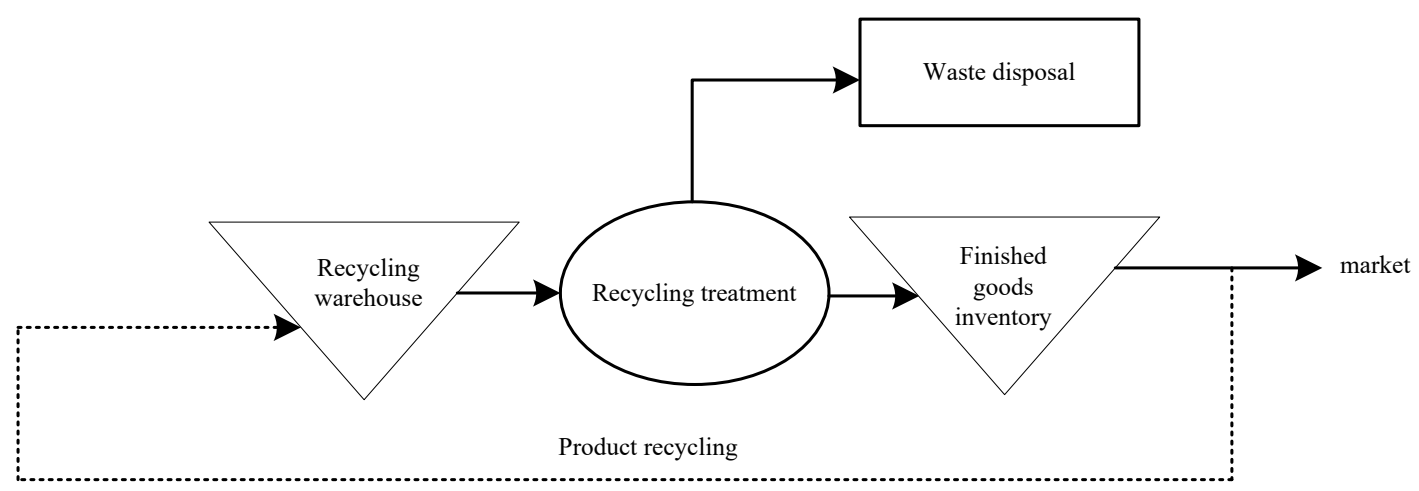

Figure 1. Structure of inventory system based on reverse logistics

Inventory is an important part of enterprise cost. Under the background of the formation of buyer's market, reducing inventory cost has become one of the main means and ways to improve profits. Inventory problem is a very important problem faced by enterprises, and inventory problem can be solved by logistics [8]. Now many experts begin to study this, and clearly realize that enterprises can reduce the cost of enterprises by reducing inventory, in order to earn more profits, so logistics is indispensable for enterprises. Now many experts regard logistics management as an important part of inventory management, because logistics management can greatly reduce the inventory of enterprises, which shows that logistics management is very important for an enterprise. The most important factor to be considered in the layout of reverse logistics network is cost. In the layout of reverse logistics network, it is necessary to analyze the influencing factors of the operation cost of reverse logistics [9]. The total cost of reverse logistics operation is mainly composed of transportation cost, inventory cost, and the construction cost of each facility. In addition, it also includes management cost and personnel salary. However, considering the complexity of the research problem, the management cost and personnel salary are not considered for the time being.

In the past, there was the concept of inventory in enterprises, but the former concept of inventory is different from the present one [10]. In the past, it refers to the goods kept by enterprises. Enterprises use these goods to ensure the normal operation of enterprises. Inventory is actually to ensure the resources needed by enterprises in the future. These resources will occupy costs, but can not bring profits to enterprises at the moment [11]. With the rapid development of market economy and the increase of competition incentive, most enterprises pay more and more attention to the management of these idle resources. The key of inventory control is to save more capital on the basis of ensuring service quality, so inventory cost is the most important part in inventory control [12]. Due to the correlation between the loss factors caused by extending delivery time, it is necessary to study the inventory status of a product and clarify the relationship between it and cost. As shown in Figure 2. 


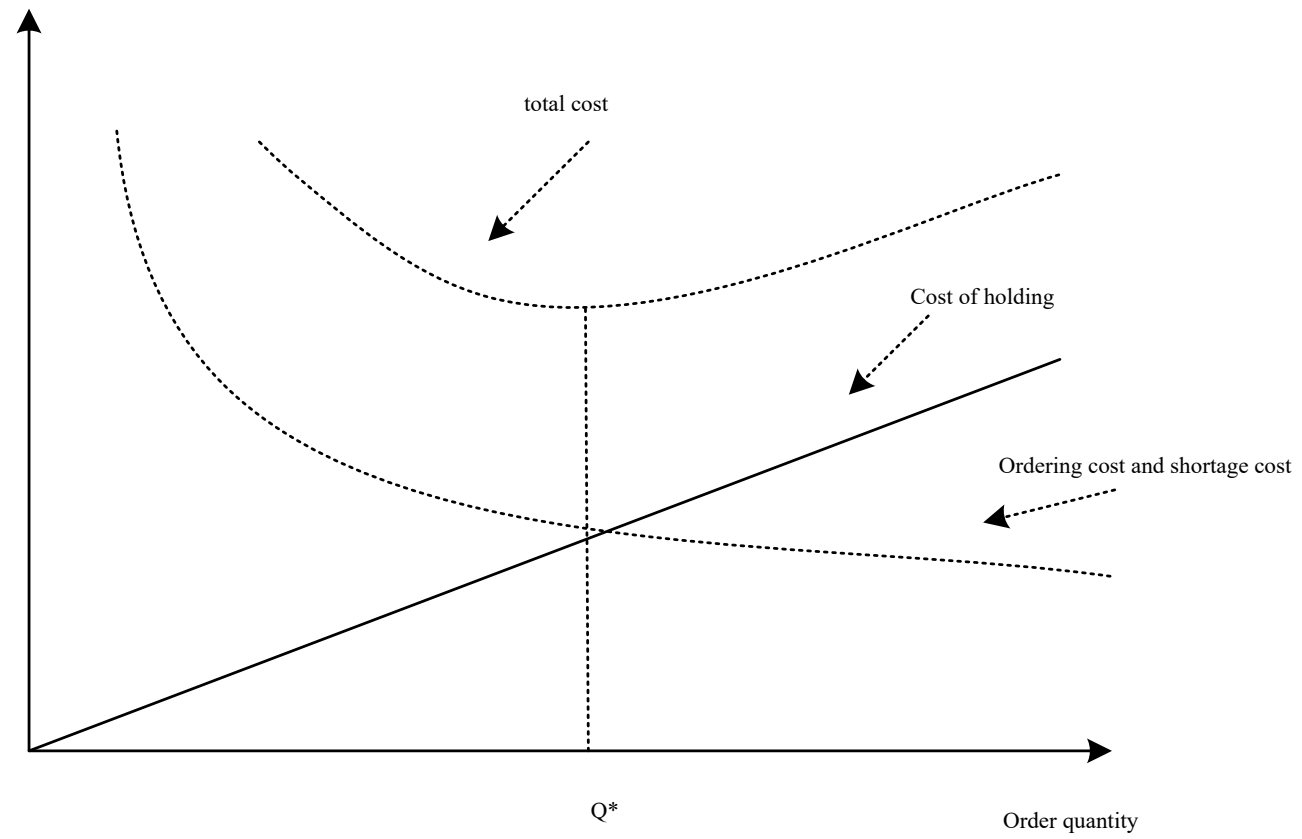

Figure 2. The reverse relationship between the quantity of unsubscribed order and the related inventory cost

For inventory control, it is necessary to check the time period of inventory, pick-up time, replenishment time, order quantity and replenishment quantity. Inventory control system is not omnipotent, such as demand, order ahead of time are not budgetable; but the order volume and quantity can be controlled in real time [13]. Based on the solution of inventory problem, what we need to do is to establish the associated data model and answer through the data model. In the manufacturing process, through the purchase of new materials and the use of recycled products to meet the market demand. At present, in order to keep up with the pace of the market and meet the taste of the public, the domestic manufacturing industry selects new materials one after another, which also puts forward higher requirements on the recycling of economic development. The recycling of products will gradually become one of the most important ways in the manufacturing process [14]. Therefore, in this sense, the reuse of recycled products is not only one of the main purposes for enterprises to reduce production costs, but also a key link for enterprises to carry out the strategic concept of circular economy and achieve the strategic goal of sustainable development [15]. It is the unfolding of reverse flow that draws a strong foundation for the concept of circular economy and the realization of sustainable development strategy Methylene blue.

\section{B. Software Operation Function of Reverse Logistics} Inventory Control System

The traditional forward logistics control model has achieved fruitful results in the research process, and the related theoretical research is also relatively mature. However, the research on inventory cost control of reverse logistics needs to be further deepened. Based on the traditional inventory cost control model, this paper studies the reverse logistics inventory cost control model. Based on the assumption that the return rate of dealers is determined and the consumption demand of enterprises is uncertain, a model is established to solve the practical problems in the process of inventory cost control of reverse logistics [16]. At present, from the current situation of enterprise product recycling, product recycling is mainly two parts: return and exchange. The former mainly refers to a kind of behavior that dealers or consumers return their purchased products for various reasons, while exchange is the behavior that dealers or consumers exchange their purchased products for the same specifications [17]. The collection points are grouped according to the quantity of each collection point and the geographical location of the collection point, and then each collection group is assigned to the alternative recovery transfer station based on the principle of minimum collection cost. Finally, the inventory control strategy of the selected recovery transfer station is determined according to the quantity of the collection, and the total system cost is calculated at this time, and the initial solution of the model is obtained. As shown in Figure 3 is the specific process of return and exchange. 


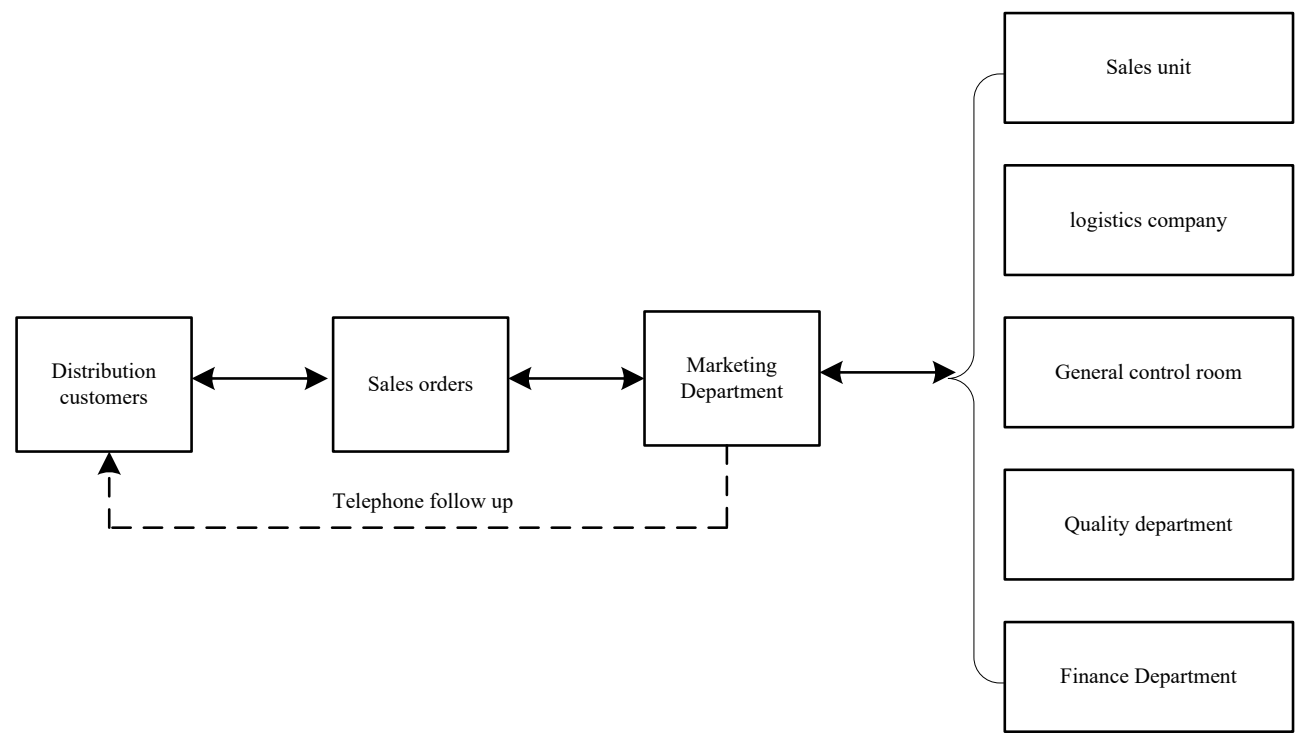

Figure 3. System return control management process

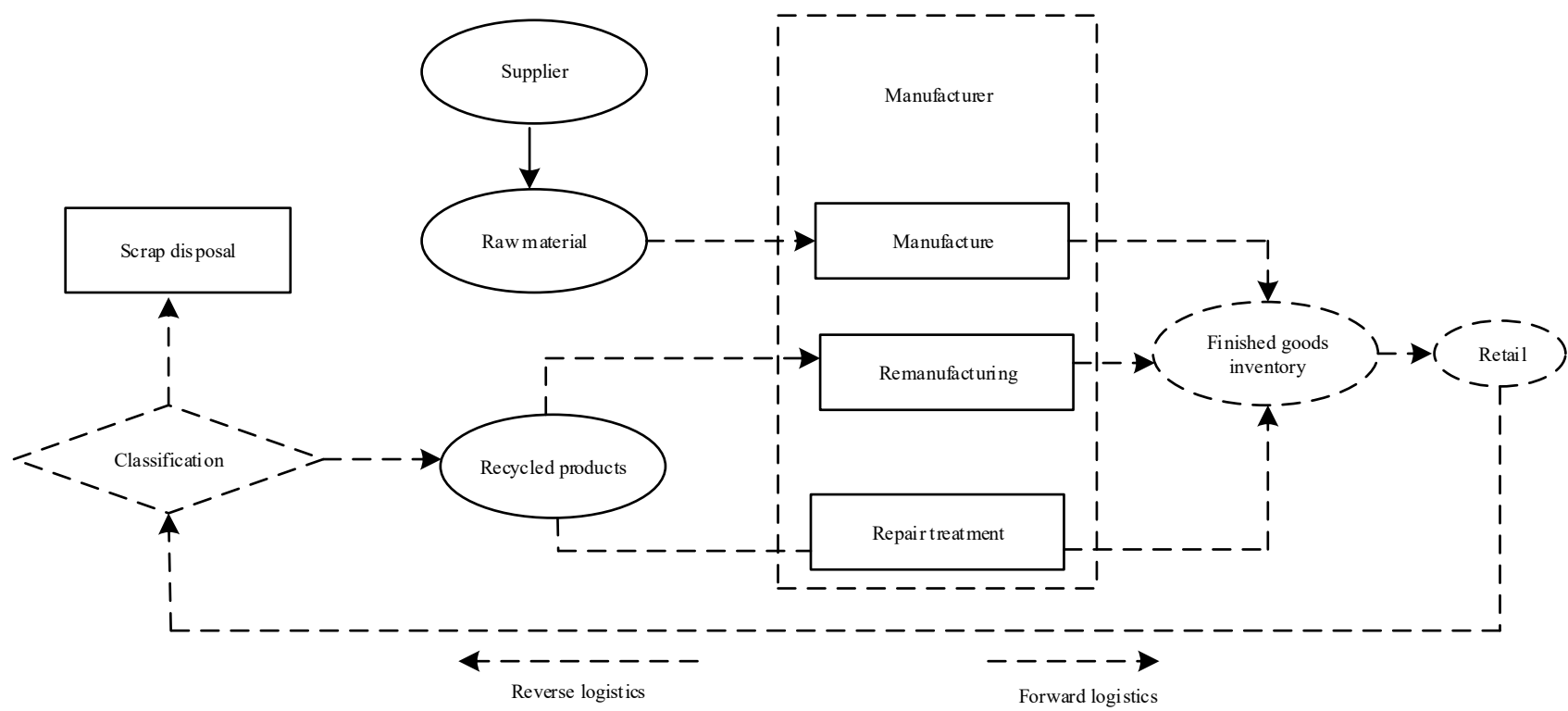

Figure 4. Optimization of data processing steps of system logistics warehouse

As can be seen from the above figure, on the basis of the initial solution, one of the selected recycling transfer stations is closed on the principle of minimum cost, and the original recycling point responsible for this recycling transfer station is rearranged to calculate the total cost of the system at this time. If the total cost of the system at this time is less than the total cost of the initial solution, the solution is retained as the current optimal solution; If the total cost of the system is greater than the total cost of the initial solution, the original solution set is retained, and then a recycle transfer station is selected to close it based on the principle of minimum cost, and the optimal solution is determined by comparing with the original solution until the last recycle transfer station is left. Reverse logistics involves many parts, so in the process of product return and exchange, how to coordinate these departments has become the most important problem in reverse logistics management [18]. However, due to the complexity of reverse logistics, enterprises often need to spend a lot of time in reverse logistics activities. The returned products generally need to stay in the warehouse for a long time, which leads to the high cost of reverse logistics and seriously affects the company's inventory management and normal production activities. From the basic situation of goods return and exchange, the main body of goods return and exchange is generally dealers, that is to say, in the process of goods return and exchange, the end consumers are generally not involved, which is different from the return and exchange of other products [19]. And this feature also makes the management in the process of product return has a certain pertinence, generally only need to manage the manufacturers and dealers, and do not need to manage the end consumers. As shown in Figure 4 is the specific process of goods return and exchange.

It can be seen from Figure 4, this paper summarizes the entire reverse logistics chain organization into four nodes: manufacturer node, supplier node, retail node, and recycling processing node. Suppliers provide manufacturers with raw materials for the production process, and designers need to complete product redesigns in the reverse logistics supply chain. In the reverse logistics of returned goods, in the 
reverse logistics of recycling, the logistics enterprises have a more comprehensive understanding of the products in the process of disassembling and restructuring the recyclables, so as to facilitate the recycling and redesign of the packaging. That ordering raw materials from outside and recycling products in reprocessing and processing are the main ways for manufacturing to meet the market demand. However, the specific quality and quantity of the returned products are not clear, so it is very difficult to manage the inventory, so as to improve the overall inventory cost; in addition, if you want to change the packaging of the returned products to sell, it is bound to increase more production costs. The above two factors are important factors affecting inventory supervision.
Whether it is to produce new products according to the requirements or to repack the returned products, it will increase the production cost of enterprises to a certain extent, and then increase the difficulty of inventory supervision [20]. Reverse logistics includes internal reverse logistics and external reverse logistics. Internal reverse logistics is the specific process of recycling defective products produced in the production process of the workshop, and the so-called external reverse logistics is the whole process of recycling products from retailers. The relationship among finished product inventory, raw material inventory and recycled product inventory is affected by inward and outward reverse logistics, which forms the relationship shown in Figure 5.

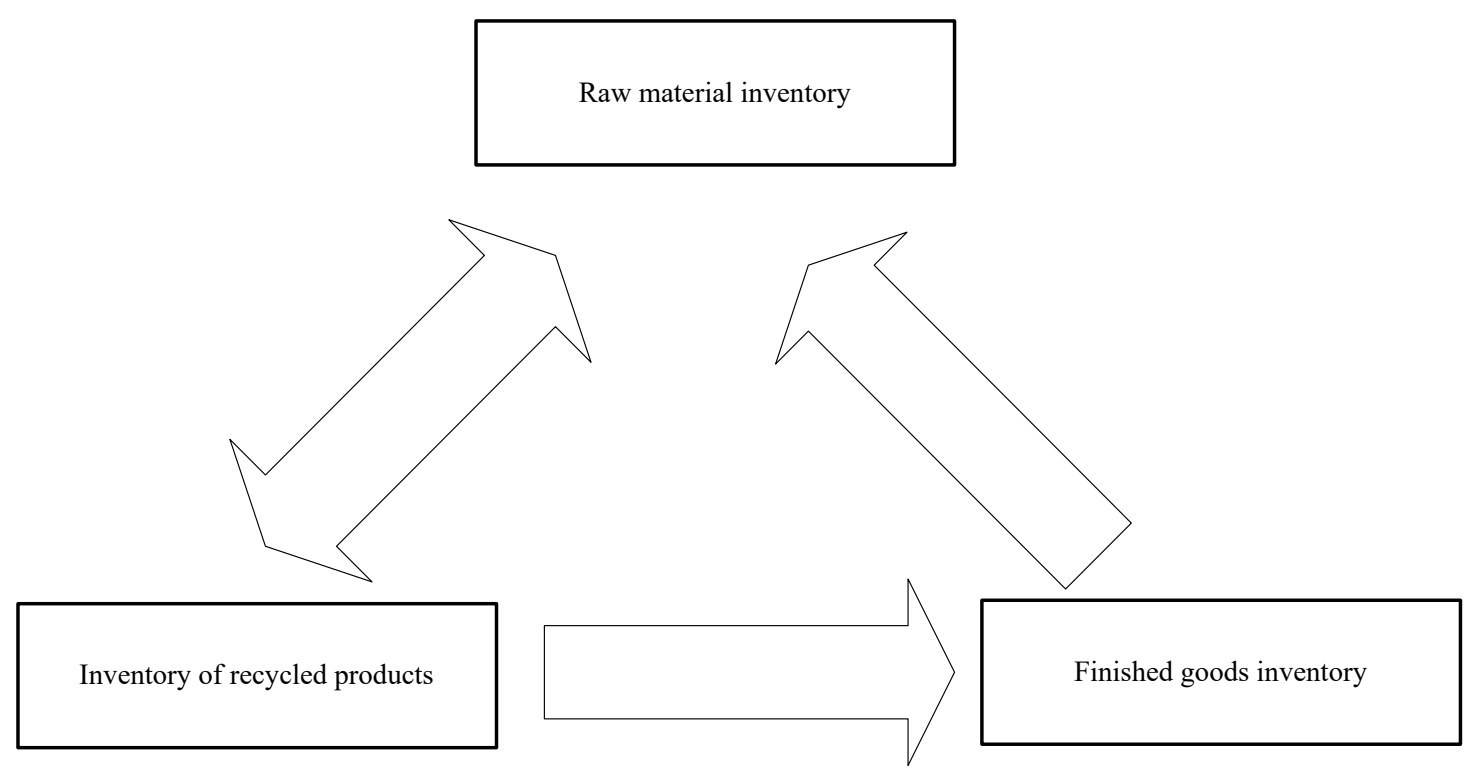

Figure 5. Module relationship structure of reverse logistics control system

With the manufacturer as the core, the dealers are responsible for recycling the products of the downstream agents at all levels, coordinating the market demand, and ordering in batches from the manufacturer. When the distributor receives the recycled products, it does not return them to the manufacturer immediately, but returns them regularly or after reaching the accumulated quantity. When scholars study the inventory model, they usually only consider the reverse logistics generated outside the enterprise. In order to simplify the model, they all assume the quantity of the market in the product demand, and also set the production period and lead time to zero [21]. Although this is beneficial to the establishment of the model and the calculation and solution of the results, but because the market environment is uncertain, it is difficult to solve. As a result, the market demand for products, so the previous model can not meet the in-depth study of modern reverse logistics [22]. The emergence of reverse logistics greatly increases the complexity of the company's logistics links, and the reverse logistics activities also lead to the management of the company's inventory cost becoming very complex. How to coordinate the relationship between forward logistics and reverse logistics has become one of the most important contents in inventory cost management. In recent years, the development of B2C is very fast, and sales have entered the $\mathrm{B} 2 \mathrm{C}$ online shopping platform. Online shopping is the general trend [23]. With the development of network technology and the popularity of online shopping, the demand for return reverse logistics is increasing. Free pick-up service will be provided within the scope of self distribution [24]. After the goods arrive at Xianwang warehouse, refund to the customer and return the goods to the supplier. Although the original return period of 7 days has been extended to 7 days after practice improvement (Figure 6), which improves customer satisfaction, the non specialization of return audit and the measures of returning goods directly to the manufacturer have reduced the level of the whole supply chain and made it difficult to overstock and deal with returned goods. 


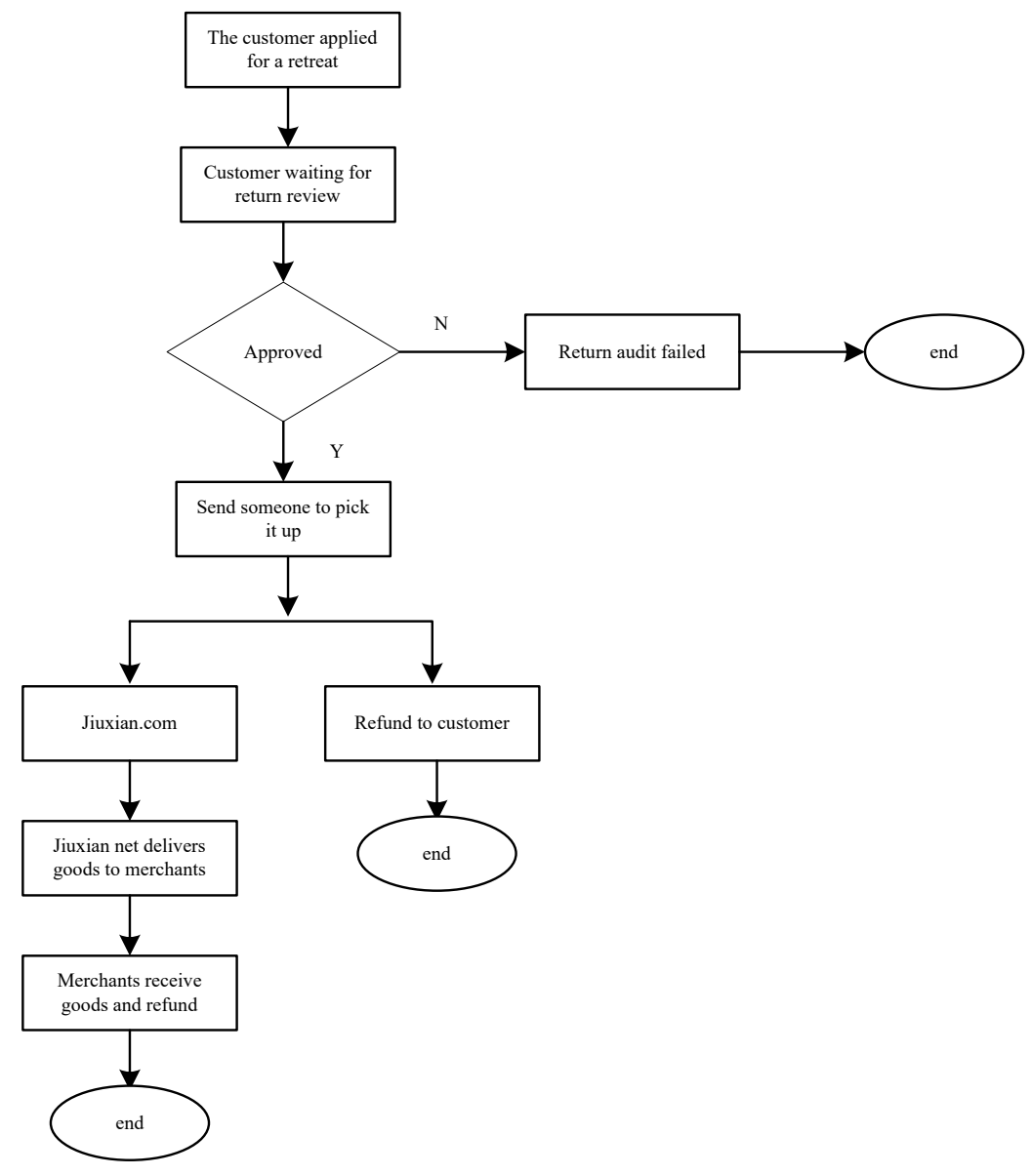

Figure 6. E-commerce guarantee recovery reverse logistics steps optimization

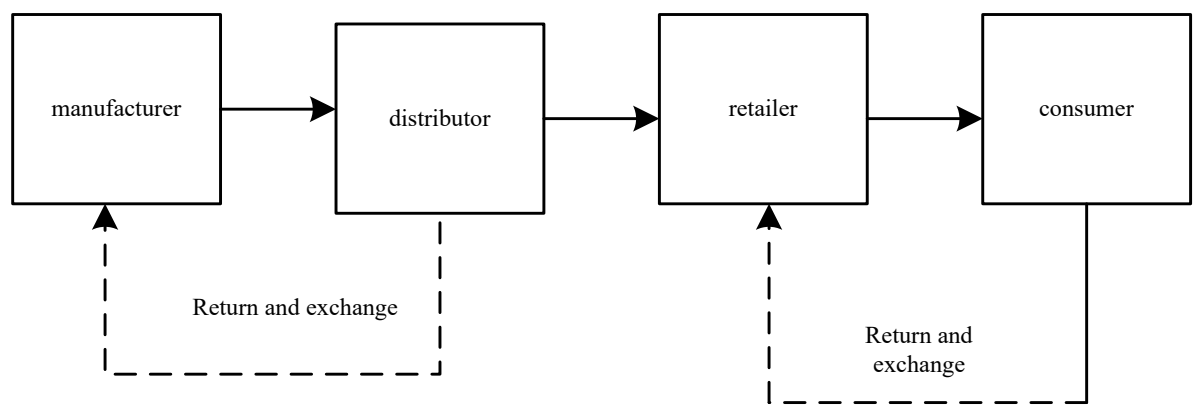

Figure 7. Reverse logistics transaction management structure

In the express industry, this problem is more prominent. The current express packaging does not have a unified standard. Express companies can design and use different types of packaging to meet the needs of customers. Consumers can also choose to package by themselves. In this way, the recycled packaging materials are various, different sizes and chaotic sizes, and it is very difficult to use them again. In order to recycle the express package, the express enterprise must carry on the standardized design to the express package size.

For the standardized design of express package size, we need to determine the module of express package first. The so-called packaging module is a standardized regulation on the basic size and series size of packaging. Generally, the basic dimension of packaging module is determined by the length, width and height of express package [25]. After designing the express box according to the packaging module, the express can be placed regularly in the process of transportation turnover, which can greatly improve the space utilization of the means of transportation, so as to realize the efficient and reasonable operation of the express logistics system. At the same time, the standardized packaging design can better adapt to the protection of products, so as to reduce the phenomenon of fillers and excessive packaging, and reduce white pollution. In the actual market, the product from the manufacturer to the consumer has experienced multi-layer participants, and there are many intermediate links. Through the analysis of the actual situation, it is found that in the traditional sales channels, manufacturers only accept the return and exchange of goods from dealers, so the participants of reverse logistics can be simplified as manufacturers and dealers. The specific transaction subjects are mainly as shown in Figure 7.

In this reverse logistics system, this paper assumes that 
the demand of the consumer market faced by the producer is random and conforms to the normal distribution. Since the sales of the obvious light season, the assumption of normal distribution is in line with the actual situation. In practice, because the cost of shortage is much higher than the inventory cost, dealers usually set up safety stock. Dealers often use the regular quantitative strategy to check and order. The dealers check the inventory once every cycle T. If the inventory is less than the safety stock, order the order quantity is Q; if the inventory is larger than the safety stock, the products larger than the safety inventory are sold first, and then the order quantity is also Q. For the treatment of returned goods, the dealers shall directly return them to the manufacturer. Therefore, there is a certain time for the recovery of returned and exchanged goods, assuming that the recovery and repair time of the products is $t$. Because the information level of offline sales channels is not high, the producers in this section mainly make production batch through the return rate of products, assuming the return rate is $b$. The cost of finished product inventory includes the cost of new product inventory and the cost of repairing goods, and the cost of new product inventory:

$$
C_{5}=\frac{1}{2} c_{N} Q(1-b) T
$$

Repair inventory cost:

$$
C_{6}=\frac{1}{2} c_{H} \min (Q, G)\left(T^{2}-t_{h}^{2}\right)
$$

Profit of production enterprise:

$$
\pi=R-\left(C_{1}+C_{2}+C_{3}+C_{4}+C_{5}+C_{6}\right)
$$

The results are as follows:

$$
\begin{aligned}
& \pi=p \min (Q, D)-c_{w} Q(1-b)-c_{w 0} \\
& -c, b \min (D, Q)-c_{r 0}-c_{0}- \\
& w_{l} b(Q-\min (Q, D))-\frac{1}{2} c_{H} \min (Q, G)\left(T^{2}-t_{h}^{2}\right)
\end{aligned}
$$

The maximum expectation value of profit function is obtained to obtain the optimal solution.

$$
E(\pi)=E(R-C)=E(R)-E(C)
$$

If:

$$
\frac{\partial E(\pi)}{\partial Q}=\frac{\partial E(R)}{\partial Q}-\frac{\partial E(C)}{\partial Q}=0
$$

Then:

$$
E(R)=p\left(\int_{0}^{0} D f(D) d D+\int_{Q}^{+\infty} Q f(D) d D\right)
$$

The results are as follows.

$$
\int_{e}^{+\infty} f(D) d D=\frac{c_{w}(1-b)+w_{2} b+\frac{1}{2} c_{N}(1-b) T}{p-c, b+w_{2} b-\frac{1}{2} c_{H}\left(T^{2}-t_{h}^{2}\right)}
$$

When the order quantity $\mathrm{Q}>0$, then:

$$
\begin{aligned}
& \lim _{e \rightarrow+\infty} \frac{\partial E(\pi)}{\partial Q}= \\
& \left(1-\int_{0}^{g} f(D) d D\right)\left[p-c, b+w_{2} b-\frac{1}{2} c_{H}\left(T^{2}-t_{h}^{2}\right)\right]- \\
& c_{r}(1-b)-w_{2} b-\frac{1}{2} c_{N}(1-b) T= \\
& -c_{w}(1-b)-w_{2} b-\frac{1}{2} c_{N}(1-b) T<0
\end{aligned}
$$

The processing cost of unsalable products at the end of the period is calculated as follows:

$$
1-\int_{0}^{Q^{+}} f(D) d D=\frac{c_{n}(1-b)+w_{2} b+\frac{1}{2} c_{N}(1-b) T}{p-c, b+w_{2} b-\frac{1}{2} c_{H}\left(T^{2}-t_{h}^{2}\right)}(10)
$$

According to the characteristics of the inventory model, we can get the following conclusions.

$$
\begin{aligned}
& I(t)=Q-d t+\sum_{i=1}^{j-1} N_{i}, \\
& (j-1) \mathrm{T} \leq t<j \\
& T(j=1,2, \ldots \ldots, n)
\end{aligned}
$$

Due to the products processed every time $t$, there are:

$$
N_{j}=N(T), \quad j=1,2, \ldots \ldots, n-1
$$

So the average inventory of the whole order cycle is:

$$
\begin{aligned}
& \frac{1}{n T} \int_{0}^{n T} I(t) d t= \\
& \frac{1}{n T}\left[\int_{0}^{T} I(t) d t+\int_{T}^{2 T} I(t) d t+\ldots . .+\int_{(n-1) T}^{n T} I(t) d t\right]= \\
& Q-\frac{d}{n T} \int_{0}^{n T} t d t+\frac{1}{n T}[1+2+3+\ldots \ldots+(n-1)] \lambda T^{2}
\end{aligned}
$$

So the average inventory cost of saleable products in the whole order cycle is:

$$
h_{s}\left[Q-\frac{1}{2} d n T+\frac{1}{2}(n-1) \lambda T\right]
$$

The inventory cost of the product is:

$$
E\left[W_{j}\right]=j / \lambda
$$

According to the relevant theories of probability theory and queuing theory, the following conclusions are obtained.

$$
\begin{aligned}
& h_{r} E\left[\left(T-W_{1}\right)+\left(T-W_{2}\right)+\ldots \ldots+\left(T-W_{\lambda T}\right)\right\rfloor \\
& =h_{r}\left[\lambda T^{2}-E\left(W_{1}+W_{2}+\ldots \ldots+W_{\lambda T}\right)\right] \\
& =h_{r}\left[\lambda T^{2}-\left(\frac{1}{\lambda}+\frac{2}{\lambda}+\frac{3}{\lambda}+\ldots \ldots+\frac{\lambda T}{\lambda}\right)\right] \\
& =h_{r} \frac{\lambda T^{2}-T}{2}
\end{aligned}
$$

Then, the inventory cost of products waiting for repair in the whole order cycle (nT) is: 


$$
\mathrm{s}=n h_{r} \frac{\lambda T^{2}-T}{2}
$$

The average total cost of the whole order cycle is:

$$
\begin{aligned}
& C(Q, T)=h_{s}\left[Q-\frac{1}{2} d n T+\frac{1}{2}(n-1) \lambda T\right]+ \\
& h_{r} \frac{\lambda T-1}{2}+\frac{C_{r 0}}{T}+C_{r} \lambda+\frac{C_{0}+K Q}{n T}
\end{aligned}
$$

The main reason why express companies are reluctant to carry out packaging recycling is that the recycled packaging is difficult to reuse, and the fundamental reason is the lack of standardized packaging. In order to solve this problem, it is necessary to carry out standardized design for the use of express packaging. The newly designed packaging should conform to the characteristics of environmental protection, lightness, not easy to be extruded and deformed, and easy to be recycled, which is conducive to improving the recycling rate. Based on the traditional inventory cost control model, this paper studies the reverse logistics inventory cost control model. Through the specific implementation of reverse logistics related assumptions, assuming that the return rate of dealers is determined and the consumption demand of enterprises is uncertain, the model is established to solve the practical problems in the process of reverse logistics inventory cost control.

\section{The Realization of Reverse Logistics Inventory}

\section{Control}

In transportation and other industries, some packaging can be used repeatedly, such as cartons, glass bottles, containers, pallets, etc. For such large packages as containers, they are usually stored in the container yard when they are not in use. If there is a need to use containers, the containers will be sent to the place where they need to be used, and the empty containers after use will be sent back to the container yard from the receiving party for simple cleaning and maintenance. For packaging like glass bottles, they can be reused with simple cleaning and testing. Then use the reverse network.

The value of recycled waste products is generally low, such as waste metal, plastic, paper, glass, etc., but the recycling process requires the use of advanced treatment technology and special equipment, and the investment cost is high. Therefore, the recycling center is often built in a centralized way, which is convenient for the centralized treatment of large quantities of waste products to achieve economies of scale. In general, the structure of recycling reverse logistics network is relatively simple, as shown in Figure 8 .

The reason of remanufacturing reverse logistics is that the economic value can be recovered by repairing the recycled products. The object of remanufacturing is high value products, such as engine, electromechanical equipment, electronic components, etc. During the optimization design of the sales return operation process, the control point standards of the platform sales return operation process are described, as shown in Table 1.

As the remanufacturing process is closely related to product production, the process is often completed by the original product manufacturer. Considering that the repaired products need to be put into the market again for sales activities, which coincides with the market of traditional new products, the remanufacturing reverse logistics network and forward logistics distribution network can be integrated to form a multi-level, closed-loop logistics network. Based on the current express business process, the reverse logistics system for express packaging recycling is designed, and its system structure is shown in Figure 9. At present, the express business process is mainly composed of five steps: receiving, packaging, transportation, sending and signing.

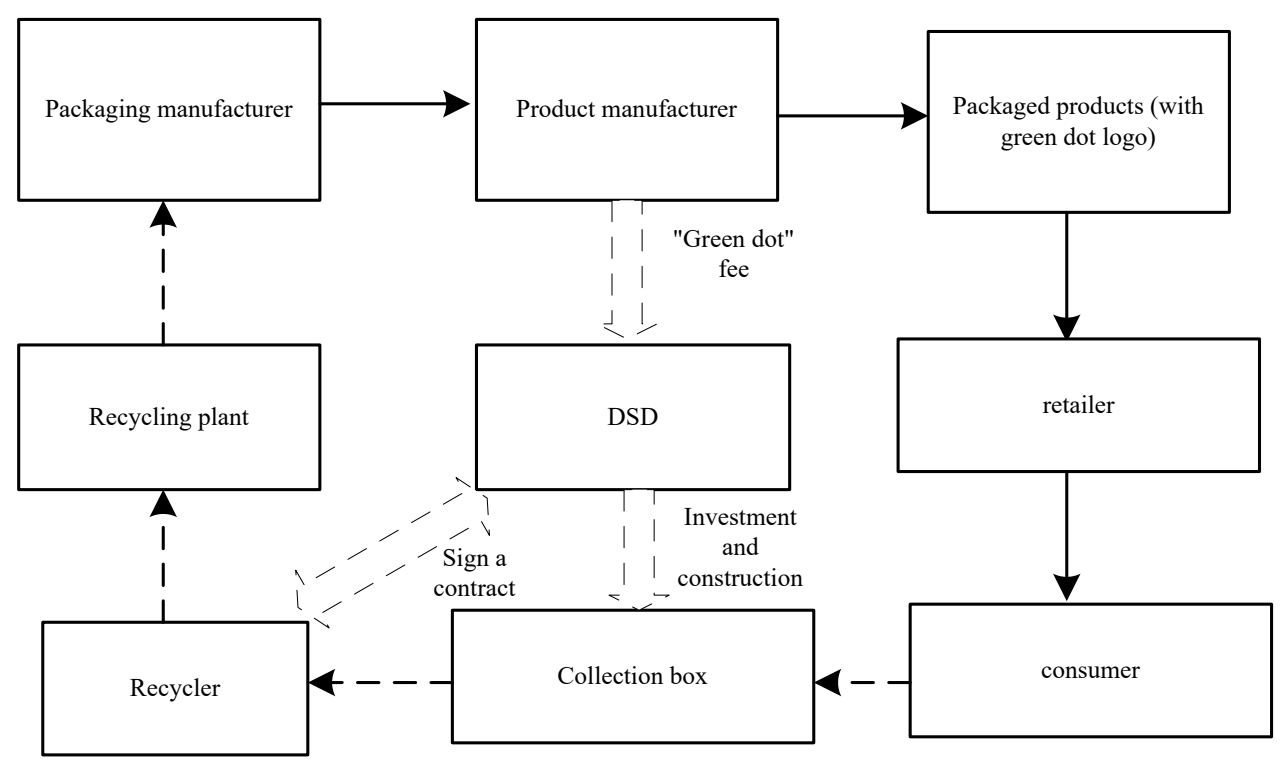

Forward logistics $\quad-\begin{gathered} \\ \text { D }\end{gathered}$

Figure 8. Structure and function optimization of DSD packaging reverse logistics control system

Table 1. Operation control description of reverse logistics of the system 


\begin{tabular}{cc}
\hline Step & Control name \\
\hline 01 & Apply for return \\
02 & $\begin{array}{c}\text { Record reason / pull / return } \\
\text { to warehouse }\end{array}$ \\
03 & $\begin{array}{c}\text { There are more than 5 people } \\
\text { in the sales and return queue }\end{array}$ \\
& \\
& \\
04 & $\begin{array}{c}\text { Inform the document } \\
\text { supplement and the unit to } \\
\end{array}$ \\
& receive the goods
\end{tabular}

05

Arrange drivers to line up to receive the goods

06 Weighing and testing of goods to be returned

07 In line with the sales return standard

08 Refuse, driver take away

09

Confirm the signature on the customer's receipt
The driver should clearly indicate the reason for backing up in the document (or system)

There are 1-2 standard personnel for each warehouse;

When there are more than 5 drivers queuing up to return goods on site, the sales return personnel shall inform the return supervisor to increase the manpower, including all callable return personnel and document personnel, and inform the designated person in charge of Meixian delivery to maintain order on site;

In case of frequent and centralized return of goods by drivers, the salesmen should timely feed back the abnormalities to the regional warehouse quality control, and observe the rules to make typesetting adjustment

The independent return area is set, and the non return area is equipped with two tables to separate the driver from the return personnel, and two electronic scales are equipped;

When going back, it should be clearly marked, and attached with the name, telephone number and photo of the return supervisor and the person in charge of Meixian delivery site;

The driver should be patient to persuade the driver to wait for the goods to be received if there are less than 5 people in line at the scene

Weigh the actual goods and check whether the goods are consistent with the documents

According to the inspection standard of sales return

If not, communicate with the driver patiently and return the goods to the driver

Black ball point pen, a line on the receipt, cross out the whole line;

On the last side of the marking part, the sales return officer shall sign for confirmation and affix the seal of sales return at the signing place;
Sales returnees

Responsible

post

customer

driver

Sales returnees

Sales returnees

Sales returnees

driver

Sales returnees

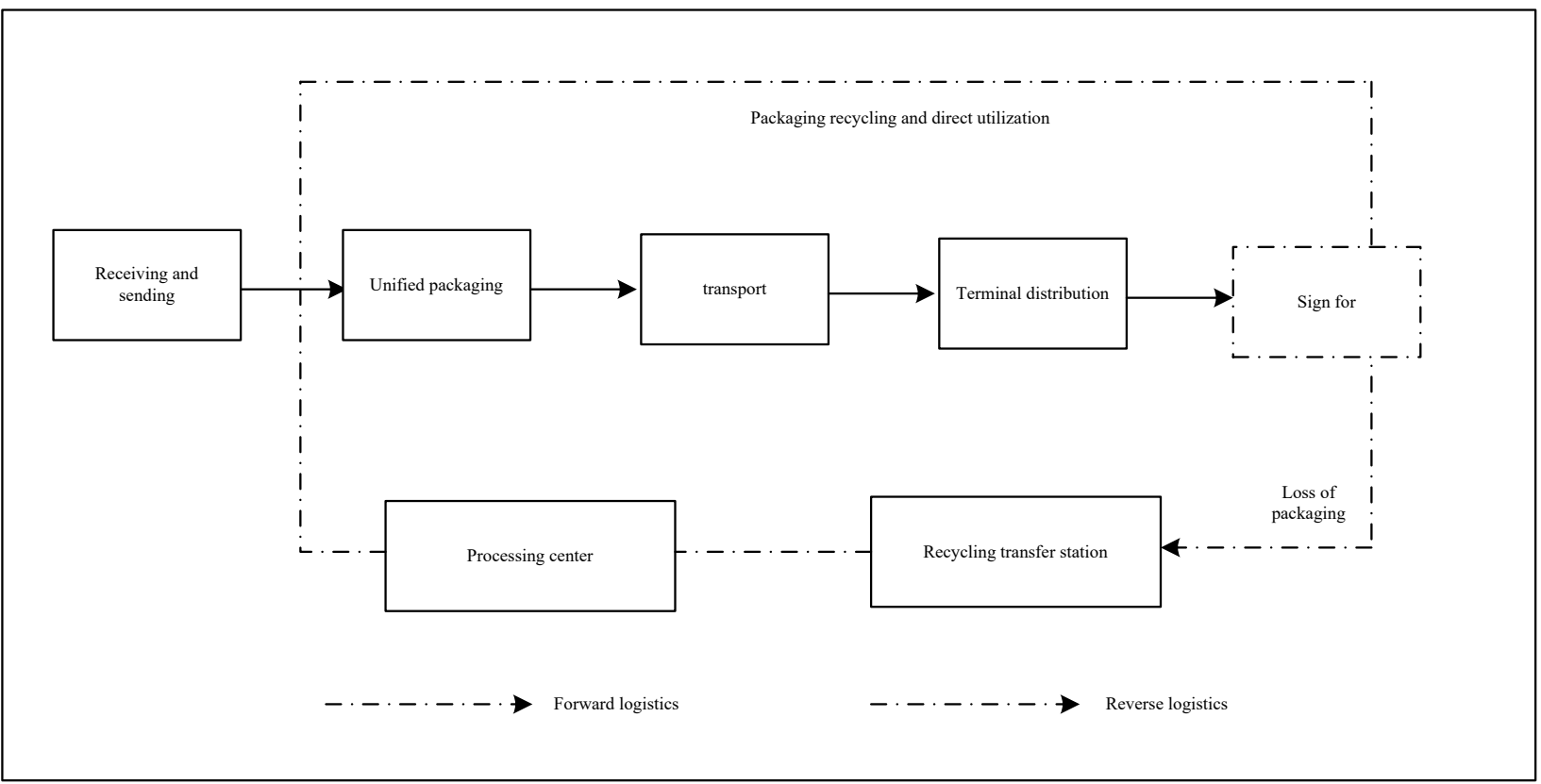

Figure 9. Reverse logistics management system of express packaging

The main reason why express companies are reluctant to carry out packaging recycling is that the recycled packaging is difficult to reuse, and the fundamental reason is the lack of standardized packaging. In order to solve this problem, it is necessary to carry out standardized design for the use of express packaging. The newly designed packaging should conform to the characteristics of environmental protection, lightness, not easy to be extruded and deformed, and easy to be recycled, which is conducive to improving the recycling rate. The standardized design of express packaging mainly 
considers from three aspects: the selection of packaging materials, packaging size and express packaging. Such as the packaging of household appliances, beverages, and bulk commodities. The industries that re-use packaging reasonably include beer and beverage industries, and recyclable supplies such as glass, plastic bottles, and paper packaging. Especially with the popularity of online shopping, in the current business of online shopping ordering products, errors in the ordering process of consumers or errors in the delivery of goods occur from time to time.

\section{ANALYSIS OF EXPERIMENTAL RESULTS}

In order to verify the effect of the reverse logistics inventory control of the research method and the control decision at different costs, the method proposed by Dutta et al. [2] is compared with the traditional method and this method. To verify the effectiveness and solution of the algorithm, the enterprise examples and standard calculation examples are simulated and tested respectively. The specific experimental environment is shown below. Client software environment: Windows 8 operating system, Dreamweaver CS5 development platform; client software environment: Windows Server 2012 operating system. A commercial server is used to deploy the experimental environment, and the client is connected through the Internet for program access. The specific hardware environment is described in Table 2.

Based on the above environment, using Excel to analyze the demand, we can get the system operation efficiency characteristic diagram as shown in Figure 10.

Table 2. Experimental environment settings

\begin{tabular}{cc}
\hline Name & Remarks \\
\hline CPU & Quad core processor \\
Chip & NVIDIAGeForceGT750M independent \\
Hard & graphics card \\
disk & $6000 \mathrm{rpm}$ \\
Memory & RPM \\
\hline
\end{tabular}

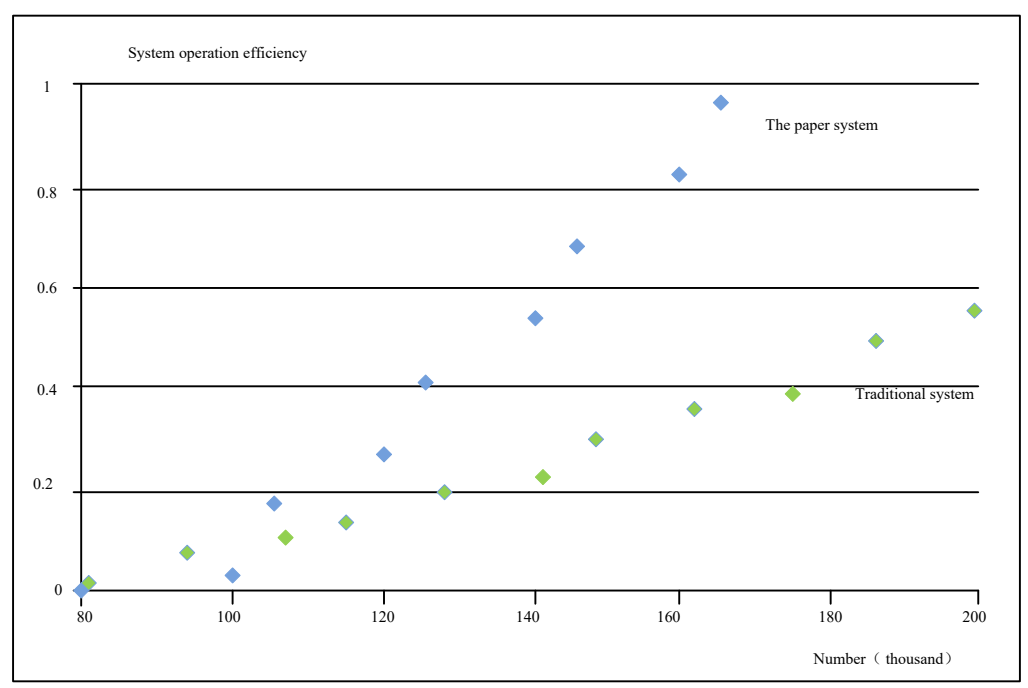

Figure 10. Comparison and detection of system operation efficiency

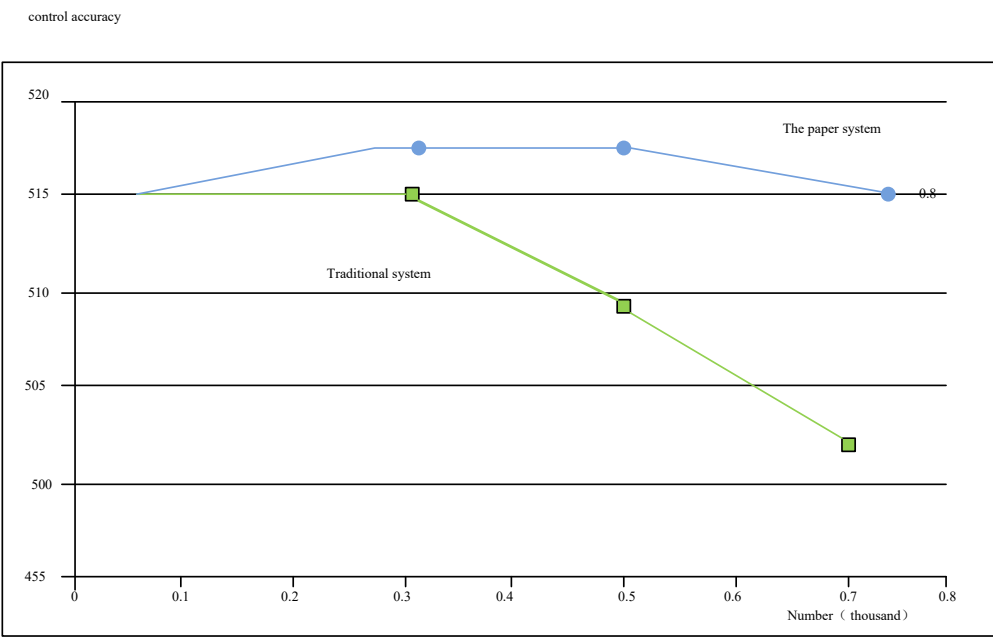

Figure 11. Comparison and detection of system control effect

Under the condition that the periodic demand approximately obeys the normal distribution, the efficiency of this system is obviously higher in the actual control and management process. The stability test results of the control system can be obtained by further calculation, as shown in Figure 11. 
According to the data analysis, this system has high control accuracy and efficiency in the use process. Because the optimal production lot $\mathrm{Q}$ and the maximum expected profit $\mathrm{e}(\mathrm{R})$ are inversely proportional to the product transportation rate $\mathrm{b}$, that is, the larger the product transportation rate is, the lower the optimal production lot and the maximum expected profit are. Therefore, the manufacturer should improve the quality, strictly control the transportation rate, and reach an agreement with the dealer on transportation matters standard. Under the condition that other conditions remain unchanged, increase the value of recovery rate a in turn. At this time, the production order cycle, total production time, order quantity, average total cost can be obtained from the formula in turn, and the production lead time $\mathrm{L}_{\mathrm{t}}=0.2 \mathrm{~T}$. Their changes are shown in Table 3.

Table 3. Comparison of decision quantity of reverse logistics under different recovery rates

\begin{tabular}{|c|c|c|c|c|c|}
\hline $\begin{array}{l}\text { Rec } \\
\text { ove } \\
\text { ry a }\end{array}$ & $\begin{array}{l}\text { Producti } \\
\text { on order } \\
\text { cycle T* }\end{array}$ & $\begin{array}{c}\text { Produ } \\
\text { ction } \\
\text { lead } \\
\text { time } \\
\text { Lt }\end{array}$ & $\begin{array}{c}\text { Total } \\
\text { productio } \\
\text { n time } \mathrm{t}^{*}\end{array}$ & $\begin{array}{l}\text { Product } \\
\text { cycle } \\
\text { order } \\
\text { quantity } \\
\text { Q* }^{*}\end{array}$ & $\begin{array}{l}\text { Avera } \\
\text { ge } \\
\text { total } \\
\text { cost } \\
\text { C }^{*}\end{array}$ \\
\hline $\begin{array}{c}0.1 \\
5\end{array}$ & 5.75 & 1.15 & 2.02 & 85.82 & 363.55 \\
\hline $\begin{array}{c}0.2 \\
5\end{array}$ & 5.89 & 1.18 & 1.88 & 82.93 & 365.84 \\
\hline $\begin{array}{c}0.3 \\
5\end{array}$ & 6.08 & 1.22 & 1.75 & 79.84 & 366.89 \\
\hline $\begin{array}{c}0.4 \\
5\end{array}$ & 6.31 & 1.26 & 1.61 & 76.24 & 366.32 \\
\hline $\begin{array}{c}0.5 \\
5\end{array}$ & 6.62 & 1.32 & 1.48 & 72.36 & 364.10 \\
\hline $\begin{array}{c}0.6 \\
5\end{array}$ & 7.01 & 1.40 & 1.35 & 54.54 & 311.26 \\
\hline $\begin{array}{c}0.7 \\
5\end{array}$ & 7.54 & 1.51 & 1.21 & 50.82 & 309.42 \\
\hline
\end{tabular}

From the table, it can be seen that when the recovery rate a is greater than 0.65 , the total production time has been less than the production lead time, which indicates that the returned products have been sufficient to meet the demand, that is, the manufacturer can meet the product demand of the market without further production in advance. In general, the recovery rate has a great influence on the inventory decision-making involved above. In the actual production, the recovery rate is also an important reference index used by most enterprises to control the cost of enterprises. But as far as the recovery rate of products is concerned, whether it is the prediction of it or the development of recycling work, it is a very difficult task for the enterprises now. But it is undeniable that the effective adjustment of the recovery rate can make the order cycle, ordering cost and inventory cost of the manufacturer reach a best balance point, so that the enterprise can get more profits. In the actual market, the inventory model under the condition of allowing shortage is not only the recovery rate, but also an important index of unit shortage cost. Recycled products need to be classified and inspected. Recycled products that do not meet the requirements are treated as waste, and the rest are left in the recycled product inventory for remanufacturing. Therefore, this paper chooses two recovery rates to change the unit shortage cost to analyze the sensitivity of four decision variables under the condition that the other conditions are unchanged. Their changes are shown in Table 4 and Table 5.

Table 4. Comparison of the change of decision-making of reverse logistics control under the cost of shortage of different units

\begin{tabular}{|c|c|c|c|c|}
\hline $\begin{array}{c}\text { Unit } \\
\text { shortage } \\
\text { cost } \mathrm{h}_{3}\end{array}$ & $\begin{array}{l}\text { Produc } \\
\text { tion order } \\
\text { cycle } T^{*}\end{array}$ & $\begin{array}{c}\text { Order } \\
\text { quantity } \\
Q^{*}\end{array}$ & $\begin{array}{c}\text { Maxim } \\
\text { um } \\
\text { shortage } \\
\text { B }\end{array}$ & $\begin{array}{l}\text { Avera } \\
\text { ge total } \\
\text { cost } \mathrm{C}^{*}\end{array}$ \\
\hline 10 & 6.06 & 65.93 & 32.97 & 463.94 \\
\hline 20 & 5.25 & 57.12 & 19.05 & 514.8 \\
\hline 30 & 4.95 & 53.86 & 13.47 & 537.98 \\
\hline 40 & 4.79 & 52.12 & 10.42 & 551.23 \\
\hline 50 & 4.70 & 51.14 & 8.52 & 559.84 \\
\hline 60 & 4.63 & 50.37 & 7.20 & 565.87 \\
\hline 70 & 4.58 & 49.83 & 6.23 & 570.34 \\
\hline
\end{tabular}

Table 5. Comparison of reverse logistics control decision quantity under different unit shortage cost $(\mathrm{a}=0.65)$

\begin{tabular}{ccccc}
\hline $\begin{array}{c}\text { Unit } \\
\text { shortage } \\
\text { cost } \mathrm{h}_{3}\end{array}$ & $\begin{array}{c}\text { Productio } \\
\mathrm{n} \text { order } \\
\text { cycle } \mathrm{T}^{*}\end{array}$ & $\begin{array}{c}\text { Order } \\
\text { quantity } \\
\mathrm{Q}^{*}\end{array}$ & $\begin{array}{c}\text { Maximu } \\
\mathrm{m} \\
\text { shortage } \\
\mathrm{B}\end{array}$ & $\begin{array}{c}\text { Average } \\
\text { total cost } \\
\mathrm{C}^{*}\end{array}$ \\
\hline 10 & 7.18 & 55.69 & 27.85 & 626.91 \\
20 & 6.21 & 48.19 & 16.06 & 670.06 \\
30 & 5.86 & 45.45 & 11.36 & 689.58 \\
40 & 5.68 & 44.08 & 8.83 & 700.77 \\
50 & 5.56 & 43.15 & 7.19 & 708.03 \\
60 & 5.48 & 42.52 & 6.07 & 713.13 \\
70 & 5.43 & 42.13 & 5.27 & 716.91 \\
\hline
\end{tabular}

From this we can know that when the recovery rate is small, the unit shortage cost has a greater impact on the average total cost. This is because in the case of low recovery rate, the returned products are not enough, and the products that can be used to replenish the inventory are not as many as when the recovery rate is high. In addition, the development trend of the average total cost is also consistent with the actual situation, because with the increase of shortage cost, the production enterprises have to shorten the order cycle, improve the inventory storage and reduce the shortage in order to obtain greater profits, and this decision-making behavior is bound to increase the corresponding average total cost.

\section{DISCUSSION}

With people's increasing attention to environmental protection, many legislations require manufacturers to be responsible for the whole life cycle of products, which makes reverse logistics more and more concerned by all sectors of society. Foreign research in this field has made some achievements and has been applied in practice. China's research in this field has just started, the theory and practice lag behind foreign countries, the relevant inventory model research is also limited, and the practice of enterprises is even less.

We designed the reverse logistics inventory control system of e-commerce packaging recycling from the 
hardware and software parts respectively. The inventory cost of finished products, including the inventory cost of new products and the cost of repaired goods, and the relationship between the inventory cost of new products are calculated. Here we simplify the calculation process and optimize the efficiency of the algorithm. Experiments show that the system designed in this paper has strong advantages in inventory control.

\section{CONCLUSIONS}

Reverse logistics can be continuously developed under the background of the development of circular economy, and recycling and utilization of waste or surplus logistics along the opposite direction of product manufacturing and production, which can greatly reduce the cost of materials in the production of enterprises, and indirectly play a positive role and significance in the management of production cost and inventory cost. That is to say, the related problems of reverse logistics are closely related to the inventory cost management of enterprises. In previous studies, some have proposed multi-objective logistics network models, and some have used the Hybrid Fuzzy Multi-Criteria Decision Making (MCDM) method to help companies select and evaluate different third-party reverse logistics providers, which provides an opportunity for logistics network operations. Certain help. But it also needs to improve the algorithm flow.

This paper takes Shanxi as an example, from the perspective of reverse logistics, distinguishes the network sales mode and the traditional sales mode, and makes a comprehensive study on the enterprise inventory management and inventory control. In this paper, the basic theory of reverse logistics is studied and analyzed in a paved way; Secondly, it points out the particularity of reverse logistics inventory control and the status quo and influencing factors in the process of reverse logistics inventory cost management. The paper defines the cost of reverse logistics inventory control in different aspects. In this paper, there are problems in inventory cost management, different network sales model and traditional sales model, and different inventory cost control models are established to make the problem more clear and solve the model. Finally, the model is analyzed by numerical examples, and the optimal control scheme and the quantity of logistics are determined. Under the guidance of the development strategy of circular economy, the optimization of cost control based on reverse logistics can be realized, and the optimization management measures of the whole inventory can be realized through reverse logistics.

\section{REFERENCES}

[1] Liu W. Route optimization for last-mile distribution of rural e-commerce logistics based on ant colony optimization. IEEE Access, 2020, vol. 8, pp. 12179-12187.

[2] Dutta P, Mishra A, Khandelwal S, et al. A multiobjective optimization model for sustainable reverse logistics in Indian E-commerce market. Journal of Cleaner Production, 2020, vol. 249, pp. 119348.

[3] Wang C N, Dang T T, Nguyen N A T. Outsourcing reverse logistics for e-commerce retailers: A two-stage fuzzy optimization approach. Axioms, 2021, vol. 10, no. 1, pp. 34.

[4] Zennyo Y. Strategic contracting and hybrid use of agency and wholesale contracts in e-commerce platforms. European Journal of Operational Research, 2020, vol. 281, no. 1, pp. 231-239.

[5] Wang Y, Fan R, Shen L, et al. Recycling decisions of low-carbon e-commerce closed-loop supply chain under government subsidy mechanism and altruistic preference. Journal of Cleaner Production, 2020, vol. 259, no. 10, pp. 120883.

[6] Abumalloh R A, Ibrahim O, Nilashi M. Loyalty of young female Arabic customers towards recommendation agents: A new model for $\mathrm{B} 2 \mathrm{C}$ E-commerce. Technology in Society, 2020, vol. 61, no. 11, pp. 101253.

[7] Collier Z A, Lambert J H. Evaluating management actions to mitigate disruptive scenario impacts in an e-commerce systems integration project. IEEE Systems Journal, 2019, vol. 13, no. 1, pp. 593-602.

[8] Alsaad A, Taamneh A. The effect of international pressures on the cross-national diffusion of business-to-business e-commerce. Technology in Society, 2019, vol. 59, no. 7, pp. 101158.

[9] Kargar S, Pourmehdi M, Paydar M M. Reverse logistics network design for medical waste management in the epidemic outbreak of the novel coronavirus (COVID-19). Science of the Total Environment, 2020, vol. 746 , no. 8 , pp. 141183 .

[10]Zarbakhshnia N, Wu Y, K Govindan, et al. A novel hybrid multiple attribute decision-making approach for outsourcing sustainable reverse logistics. Journal of Cleaner Production, 2020, vol. 242, pp. 118461.

[11] Ma Y, Li Z, Fang Y, et al. A hybrid priority-based genetic algorithm for simultaneous pickup and delivery problems in reverse logistics with time windows and multiple decision-makers. Soft Computing, 2019, vol. 23, no. 15, pp. 6697-6714.

[12] Wang J, Li H, Lu H, et al. Integrating offline logistics and online system to recycle e-bicycle battery in China. Journal of Cleaner Production, 2020, vol. 247, no. 10, pp. 119095-119099.

[13] Wang Y, Shi Q. Spare parts closed-loop logistics network optimization problems: Model formulation and meta-heuristics solution. IEEE Access, 2019, vol. 7, no. 10, pp. 45048-45060.

[14] Afra A P, Behnamian J. Lagrangian heuristic algorithm for green multi-product production routing problem with reverse logistics and remanufacturing. Journal of Manufacturing Systems, 2020, vol. 58, no. A, pp. 33-43.

[15] Dutta P, Talaulika R S, Xavier V, et al. Fostering reverse logistics in India by prominent barrier identification and strategy implementation to promote circular economy. Journal of Cleaner Production, 2021, vol. 294, no. 5, pp. 126241.

[16] Safdar N, Khalid R, Ahmed W, et al. Reverse logistics network design of e-waste management under the triple bottom line approach. Journal of Cleaner Production, 2020, vol. 272, no. 9, pp. 122662.

[17] Oyola-Cervantes J, Amaya-Mier R. Reverse logistics network design for large off-the-road scrap tires from mining sites with a single shredding resource 
scheduling application. Waste Management, 2019, vol. 100, pp. 219-229.

[18] Oliveira C D, Luna M, Campos L. Understanding the Brazilian expanded polystyrene supply chain and its reverse logistics towards circular economy. Journal of Cleaner Production, 2019, vol. 235, pp. 562-573.

[19] Chen D, Ignatius J, Sun D, et al. Reverse logistics pricing strategy for a green supply chain: A view of customers' environmental awareness. International Journal of Production Economics, 2019, vol. 217, pp. 197-210.

[20] Trochu J, Chaabane A, Ouhimmou M. A two-stage stochastic optimization model for reverse logistics network design under dynamic suppliers' locations. Waste Management, 2019, vol. 95, no. 9, pp. 569-583.

[21] Christopher Allen Pramono, Adler Haymans Manurung, Pantri Heriyati, Wibowo Kosasih, Analysis of The Influence of Entrepreneurship Capability, Agility, Business Transformation, Opportunity on Start-Up Behavior In E-Commerce Companies In Indonesia During The Covid 19 Pandemic, WSEAS Transactions on Business and Economics, 2021, vol. 18, pp. 1103-1112.

[22] Saleh Ali Alomari, Safwan Al Salaimeh, Emran Al Jarrah, Mowafaq Salem Alzboon, Enhanced logistics information service systems performance: Using theoretical model and cybernetics? Principles. WSEAS Transactions on Business and Economics, 2020, vol. 17, pp. 278-287.

[23]Zhang M, Pratap S, Zhao Z, et al. Forward and reverse logistics vehicle routing problems with time horizons in B2C e-commerce logistics International Journal of Production Research, 2021, vol. 59, no. 20, pp. 6291-6310.

[24] Chen T. Simulation of E-Commerce Logistics Terminal Distribution Route Planning During the Express Delivery Period. Computer Simulation, 2021, vol. 38, no. 3, pp. 355-359.

[25] Yang X, Han M, Tang H, et al. Detecting Defects with Support Vector Machine in Logistics Packaging Boxes for Edge Computing. IEEE Access, 2020, vol. 8, pp. 64002-64010.

\section{Creative Commons Attribution License 4.0} (Attribution 4.0 International, CC BY 4.0)

This article is published under the terms of the Creative Commons Attribution License 4.0

https://creativecommons.org/licenses/by/4.0/deed.en_US 